SEXUAL SELECTION

\section{Mating Preferences}

from our Population Genetics Correspondent

DARWIN's notebooks show that he deduced his theories of sexual and natural selection at about the same time. Sexual selection was briefly mentioned in The Origin of Species and discussed in detail in The Descent of Man published in 1871. Although direct observations of natural selection were first made around 1900, it is only in the past two decades that sexual selection has been observed experimentally. Sexual selection occurs if there are variations in the chances of mating. It usually affects the males and has always been accepted as the cause of the evolution of the special weapons such as horns and spurs used in the fighting between the males of certain species when they collect their mates.

Darwin thought that the females would also have mating preferences for particular male characteristics, especially those involved in mating displays. For a long time many naturalists refused to accept this possibility of female choice in the selection of mates, and it was left to the population geneticists to demonstrate by experiment that there were female mating preferences for males with particular genotypes. If a female Drosophila is placed in a mating chamber with one wild type and one white eyed male, observations show that the female will usually mate with the wild type male. But a male given a choice of wild type and mutant females usually shows no preference and matings take place with both females with equal frequency.

In experiments with Drosophila Ehrman showed (Amer. Nat., 101, 415 ; 1967; Genet. Res., 11, 135; 1968) that the mating success of the males could be frequency dependent: the females had a tendency to mate with those males who possessed the rarer genotypes for particular chromosomal inversions. In the latest issue of Evolution (25, 265 ; 1971), Faugères, Petit and Thibout describe experiments to analyse different components of sexual advantage. They studied the sexual vigour of the males (their ability to inseminate several females) and their success in sexual competition (the female preference for particular genotypes). They used mutant white Drosophila melanogaster and various wild type strains and their hybrids. Sexual competition was studied by giving the males or females either a limited choice of two individuals of the opposite sex, white and wild type, to mate with, or a multiple choice with ten flies of one sex and five of the other in the mating chamber. They then observed the copulations that took place. Sexual vigour was measured by the number of females which a male could inseminate in 24 hours.

As in previous experiments, the sexual competition affected only the males. The white males were always at a disadvantage. On the other hand, in sexual vigour, the hybrids, white and wild type, were superior to the pure strains, white and wild type. This shows that different factors are responsible for sexual selection and sexual vigour. Genotypes advantageous in sexual selection may not be advantageous in sexual vigour. Faugères, Petit and Thibout point out that the ethological factors that determine the advantage in sexual selection could be masked by other factors causing superior sexual vigour. This may affect not only sexual selection but also sexual isolation. When strains evolve sexual isolation (as in the experiments recently reported by Dobzhansky and Pavlovsky in Nature $(\mathbf{2 3 0}, 289 ; 1971)$, a particular strain evolves a mating preference within itself so that eventually matings take place only between members of a particular strain. This could be prevented if the male hybrids had a superior sexual vigour and could inseminate more females although they were less likely to be chosen as mates. If the hybrids are inferior in sexual vigour, however, the mating preferences will continue to evolve and will eventually produce sexual isolation between

\title{
Craters on the Earth and Moon
}

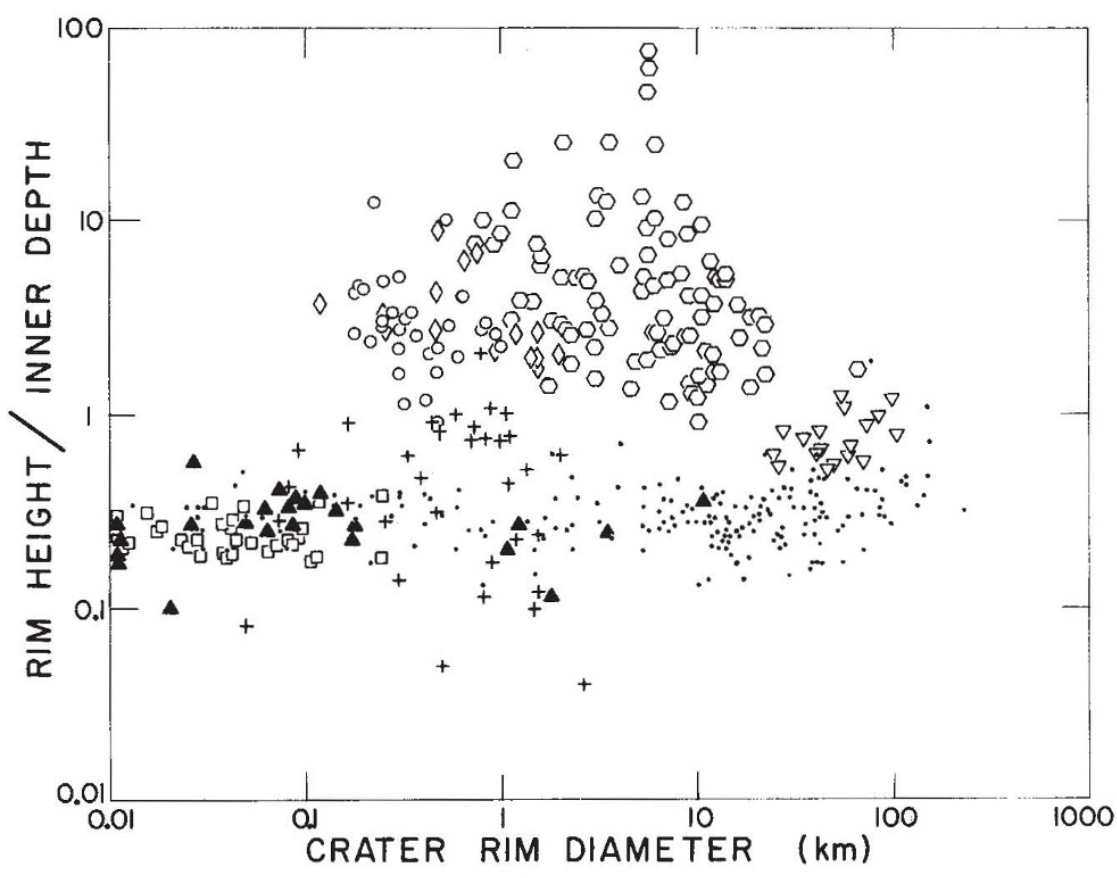

IN next Monday's Nature Physical Science R. J. Pike of the US Geological Survey, Menlo Park, California, classifies lunar craters according to the ratio of the external height of their rims to the interior depth of the craterfloor. For normal lunar craters the ratio is usually well below unity. In other words, the floors of lunar craters tend to be below the general level of the area in which they are situated.

There are exceptions of course. Lunar craters that have been flooded with mare material have ratios of external height to interior depth of about unity, and lunar craters on cones have ratios in excess of unity.

In the figure Pike has plotted the ratio of external height to interior depth against the diameter of the crater (from rim crest to rim crest) for various kinds of lunar and terrestrial craters. The dots are what he calls "normal" rimmed lunar craters, the open triangles are lunar craters filled with dark mare material, the lozenges are summit craters on lunar domes, the hexagons are terrestrial calderas, the circles are terrestrial cinder cones, the crosses are terrestrial maars (volcanic explosion craters), the squares are experimental explosion craters and the solid triangles are meteorite impact craters on the Earth.

Pike points out that the ratio of external height to interior depth, as plotted on the figure, tends to distinguish calderas, cinder cones and lunar dome craters from normal lunar craters, maar craters, meteorite craters and experimental explosion craters, and he interprets this distinction as indicating two contrasting modes of origin. Calderas, cinder cones and, presumably, lunar dome craters are essentially constructional features formed during a series of volcanic eruptions, whereas the second group of craters seem to be characterized by formation during single catastrophic explosive events. 